\title{
Teaching Multiliteracies in Scientific Discourse: Implications from Symbolic Construction of Chemistry
}

\author{
Yu Liu \\ ${ }^{a}$ Multimodal Analysis Lab, Interactive \& Digital Media Institute (IDMI), National \\ University of Singapore, 9 Prince George's Park, Singapore 118408 \\ ${ }^{\mathrm{b}}$ Institute of International Education, Sichuan International Studies University, \\ Chongqing 400031, People's Republic of China \\ e-mail: liu.yu@nus.edu.sg
}

\begin{abstract}
Recent research on science education has increasingly focused on the literacy challenges posed by multimodality. While students are required by government mandated syllabi to make a successful translation between different semiotic resources, there still remains a lack of research on the grammars and functionality of the specialized modalities to develop explicit instructions to improve literacy practices. This paper analyses the semiotic resource of chemical symbolism in secondary school chemistry textbooks with a Systemic Functional Multimodal Discourse Analysis approach (SF-MDA). It is argued that chemical symbolism is far from a jargon or mere shorthand for language. Instead, it develops unique grammatical devices to realize sub-microscopic meaning and topological meaning, which outstrips the meaning potential of language. The current study also discusses how the SF-MDA approach could develop a visible pedagogy and improve chemistry education.
\end{abstract}

Key words: Multimodality, systemic-functional theory, chemical symbolism

Science education is characterized by multimodal communication (Gilbert, 2005). Teaching and learning chemistry, for example, are

\footnotetext{
* The earlier draft of this paper was presented at the $3^{\text {rd }}$ International Redesigning Pedagogy Conference at National Institute of Education, Singapore in June 2009. Research for this article was supported by the Events in the World: Developing \& Using Interactive Digital Media for Multimodal Discourse Analysis (MDA) (NRF2007IDMIDM002-066) grant awarded by Media Development Authority (MDA) under the 1st Interactive Digital Media Research and Development (IDM R\&D) Grant Call by National Research Foundation (NRF) Singapore.
} 
implemented through the co-deployment of diverse semiotic resources including language, images, three-dimensional models, gestures, mathematical symbols as well as a unique system of chemical symbols while the complexity of chemical representations is being intensified with the introduction of innovative teaching and learning resources aided by new information and communication technologies (ICT) such as the use of web-based courseware (e.g. http://www.creative-chemistry.org.uk).

The multimodal construction of scientific knowledge poses a challenge to literacy practices, which are differentiated not only on the basis of channel and medium of communication (e.g. print, image, screen) but also according to subject areas (e.g. biology, physics, chemistry) (Unsworth, 2001, p. 10). In fact, the traditional singular notion of literacy as being able to read and write has been broadened to embrace a pluralized set of 'multiliteracies' (Cope \& Kalantzis, 2000), which have been specified as essential assessment objectives when students are required to use verbal, graphic, numerical and symbolic forms of presentation to translate one form into another (Singapore Chemistry GCE Ordinary Level (Syllabus 5067) revised for 2010, n.d., p. 2).

However, as Jones (2007, pp. 103-104) points out, current research on multimodality in science education pays scant attention to how to help students develop the diversified literacies to meet the government mandated syllabus requirements while there exists an unwarranted assumption that students already have a good command of multiliteracies. But the opposite seems to be true. Recent research (e.g. Chittleborough, 2004) reveals that even college students and secondary school science teachers have a limited understanding of chemical diagrams and symbolism, which necessitates explicit instructions on multiliteracies in science education.

This paper aims to make a modest step towards a useful pedagogy to improve literacy practices in teaching and learning chemistry at secondary schools with the approach derived from systemic-functional grammar (hereafter SFG, see Halliday, 1978, 1994), which has inspired much productive research on science and mathematics education (e.g. Halliday \& Martin, 1993; Halliday, 1998; Lemke, 1998; O’Halloran, 2000). Despite the multi-semiotic nature of chemistry education, only chemical symbolism is highlighted in this discussion, for it is far removed from young learners' sensory experience and thus might constitute the most challenging mode of representations in chemistry education. The present 
study concentrates on functional specialization of chemical symbolism and is interested in how SFG can be extended to support the pedagogy for multiliteracies.

In what follows, the main tenets of SFG are introduced to justify the theory as an appropriate approach to explore the meaning making potential of chemical symbolism. The present study then analyzes three specialized grammatical strategies chemical symbols developed and their corresponding functionality not possible undertaken by language. The final part of this research discusses pedagogical implications informed by the social semiotic analysis.

\section{METHODS}

While formal linguistic schools interpret language as an autonomous psychological phenomenon (Pinker, 1994), SFG (Halliday, 1978; Halliday $\&$ Hasan, 1985) considers language one kind of semiotic resources of the culture, whose organization is essentially related to its use in specific social context. The dialectic relationship between language and context is diagrammed in Table 1 where both language and context are modeled as stratified semiotic systems. The double headed arrow symbolizes the interstratal relationship of realization as non-random co-occurrence rather than strict determination. That is to say, language construes, is construed by, and (over time) re-construes social context (Martin, 1997, p. 4).

As Table 1 illustrates, the semogenesis of language involves operations at all the strata of the connotative and the denotative semiotics. A full discussion of all of the strata has been suggested elsewhere (e.g. Martin, 1997), but it is beyond the scope of this paper. Given that the current research focuses on the rank of discourse semantics of chemical symbolism to explore its unique functionality, the strata of register (situation of context) and lexicogrammar are carefully examined, both of which interface with discourse semantics and their inextricable connections are explained below.

The discourse semantic stratum of language is modeled through three meta-functions: ideational, interpersonal and textual, which are linguistic resources concerning with representation, interaction and information flow respectively. This intrinsic functional organization is projected on to context and redounds with three register variables of field, tenor and mode where field deals with institutional practices, tenor with social relations and 
mode with channel (Martin, 1997, p. 4). The meta-function solidarity (Martin, 1999, p. 31) between register and discourse semantics makes it possible to investigate the meaning making potential of language (as well as other semiotic resources) from the connotative semiotic system of context. On the other hand, the intrinsic functions of language are realized through lexicogrammar, which is 'the powerhouse of language' (Halliday \& Martin, 1993, p. 12). And lexicogrammar's crucial role in semantic construal is emphasized by Halliday (1994, p. xvi), who argues that without a theory of grammar, 'there is no way of making explicit one's interpretation of the meaning of a text'.

Table 1. Social Semiotic Modeling of Context and Language (adapted from Martin, 1997, p. 7)

\begin{tabular}{|c|c|c|c|}
\hline $\begin{array}{c}\text { connotative } \\
\text { semiotics } \\
\text { stratified content } \\
\text { plane }\end{array}$ & \multicolumn{3}{|c|}{ expression plane } \\
\hline \begin{tabular}{c|c|}
$\begin{array}{c}\text { Context } \\
\text { of culture }\end{array}$ & $\begin{array}{c}\text { Context of } \\
\text { situation }\end{array}$ \\
\end{tabular} & \multirow{2}{*}{\multicolumn{3}{|c|}{$\lambda$}} \\
\hline 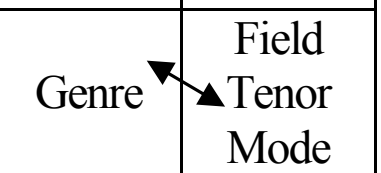 & & & \\
\hline & \multicolumn{3}{|c|}{ denotative semiotics } \\
\hline & $\begin{array}{l}\text { Discourse } \\
\text { semantics }\end{array}$ & $\begin{array}{l}\text { Lexico- } \\
\text { grammar }\end{array}$ & Phonology/Typography \\
\hline & $\begin{array}{c}\text { Ideational } \\
\text { Interpersonal } \\
\text { Textual }\end{array}$ & & 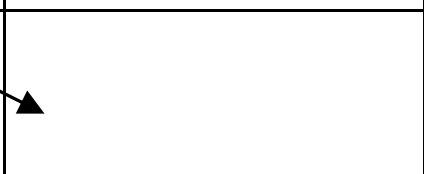 \\
\hline & \multicolumn{2}{|c|}{ stratified content plane } & expression plane \\
\hline
\end{tabular}

The dialectic relationship between the strata of register, discourse semantics and lexicogrammar might be explicated from the comparison of two linguistic nominal groups: 'an animal that has four legs' and 'a quadruped'. Although both of them could be used to interpret the same phenomenon, their different wordings make different meanings and construe different realities. For example, 'an animal that has four legs' consists of a Thing ('an animal') with a rank-shifted clause ('[[that has four 
legs]]') functioning the role of Qualifier while 'a quadruped' only has a Thing (Halliday, 1994, pp.179-196). Accordingly, the former's meaning is more transparent while the latter constructs a high level of technicality, which tends to be recognized by a person with biology knowledge. Thus the two wordings construe common sense and scientific knowledge respectively at the stratum of register.

Since the 1990s, the social semiotic account of language has been extended to explore non-verbal modalities including displayed art (O'Toole, 1994), visual design (Kress \& van Leeuwen, 1996), mathematical images and symbolism (O'Halloran, 1996, 1999, 2000, 2005 ) in which the meta-functional principle applies and grammatical descriptions loosely encompass 'the structures of relations of elements in a specific mode and between modes' (Kress, Jewitt, Ogborn, \& Tsatsarelis, 2001, p. 12). These pioneering studies develop a systemic-functional multimodal discourse analysis approach (hereafter SF-MDA, see O'Halloran, 2007), which is concerned with the meaning potential of semiotic resources distributed across strata (O'Halloran, 2008, p. 444) and thus productive to analyze the functional specialization of chemical symbolism.

Although semiotic resources including chemical symbolism simultaneously afford ideational, interpersonal and textual meta-functions, the current study, however, limits the discussion to ideational meaning making. In what follows, the semantic construal of chemical symbolism is examined from two perspectives. The first part of the discussion focuses on the historical context in which chemical symbolism evolved as a semiotic resource and the second part analyzes the specialized grammatical strategies developed by chemical symbolism. It is important to note that the contextual analysis and the grammatical examination provide a top-down and a bottom-up account of the discourse semantic stratum of chemical symbolism, both of which reveal what ideational meanings are made through the symbolic construction of chemistry.

\section{FINDINGS AND DISCUSSION}

\section{The Emergence of Chemical Symbolism}

Modern chemical symbolism appeared in response to two major historical requirements: quantification and submicroscopic interpretation. 
According to Brock (1993, p. 128), the chemical activity before the $19^{\text {th }}$ century remained qualitative and even chemists could hardly calculate the amounts of ingredients in the lab so as to perform the reaction successfully and economically, which hindered the transformation of chemistry into technology for the industrial benefits. When Dalton (1805) derided the stoichiometric way of calculating the relative weights of the particles of matter from observation and measurements (Brock, 1993, p. 135), it became possible to quantify chemistry in the early $19^{\text {th }}$ century.

On the other hand, the theoretical revolution of chemistry commencing from the late $18^{\text {th }}$ century challenged the existing interpretation based on sensory experience. For instance, the burning of charcoal used to be considered only involving the element of carbon. However, based on more enhanced technology and sophisticated instruments, Lavoisier identified burning as chemical reactions between oxygen and other elements (Brock, 1993, pp. 106-107). An alternative explanation to reveal the submicroscopic properties of chemical phenomena was therefore required.

The historical look at the evolution of chemical symbolism suggests that in terms of the register variable of field, the institutional focus of chemistry in the earlier $19^{\text {th }}$ century was not to make common sense but construe a high level of technicality to achieve quantification and submicroscopic interpretation, both of which put heavy pressure on the stratum of discourse semantics while the lexicogrammar of language can hardly realize the semantic extensions.

First of all, quantification of chemistry demands a semantic construal of topological meaning (Lemke, 1998) to describe continuous patterns of co-variation, which is, however, exceeds the meaning potential of language, whose grammatical devices contribute to typological meaning to make discrete categories. For instance, the ratio rate between the elements of a chemical compound might not be transparently indicated by its linguistic representation such as 'carbonic acid', which is self-evident in the symbolic formula of ' $\mathrm{H}_{2} \mathrm{CO}_{3}$ ' nonetheless.

Furthermore, although technical language (Halliday \& Martin, 1993) is developed to construe scientific reality, due to its grammatical features, the linguistic representation alone only provides a partial account of modern chemistry knowledge. For example, while empirical research indicates that the constituent elements equally contribute to a chemical compound, their co-equal status, however, cannot be kept in the verbal interpretation. In terms of the logical meaning of 'zinc oxide', 'zinc' 
functions as the Modifier and 'oxide' as the Head (Halliday, 1994, pp. 191192), so the former becomes subordinate to the latter and conflicts with the new scientific interpretation of composition. In contrast, the order of symbols in the chemical formula ' $\mathrm{ZnO}$ ' does not seem to imply any logical meaning of subordination, as evidenced by the historical record that the symbolic representation for water was ' $\mathrm{OH}_{2}$ ' (Oversby, 2003) instead of the present conventionalized version of ' $\mathrm{H}_{2} \mathrm{O}$ '.

\section{Specialized Grammatical Devices for Symbolic Construction of Scientific Reality}

The preceding contextual examinations of the evolution of chemical symbolism suggests that the historical requirements of quantification and interpretation of chemical phenomena at the atomic level necessitate the corresponding construal of topological meaning and submicroscopic meaning at the semantic stratum, which the lexiogrammar of language could hardly realize. On the other hand, chemical symbolism developed a series of specialized grammatical devices to bridge the gap.

\section{The reactive process}

Transitivity is a productive grammatical system to model experience at the rank of clause in language (Halliday, 1994, p. 106) and has been extended to explore the meaning potential of visual images (Kress \& van Leeuwen, 1996) and mathematical symbolism (O'Halloran, 1996, 1999, 2000, 2005). Among all the six Transitivity processes in language, only the relational process (Halliday, 1994, pp. 119-138) could be symbolized in chemistry ${ }^{1}$. Similar to mathematical discourse (O'Halloran, 2000, p. 362), the narrowed range of process types in chemical symbolism contributes to the maximal structural condensation while simultaneously allowing semantic extensions for submicroscopic interpretations not possible with language. One grammatical device to realize the required submicroscopic meaning was the development of a new type of Transitivity configuration: the reactive process.

Like the material process in language, the reactive process construes 'doing' in the world (Halliday, 1994, p. 110), but at the submicroscopic level. One significant special grammatical feature of the reactive process which it shares with the operative process in mathematics (O'Halloran, 
1996, 1999, 2000, 2005) lies in its configuration with multiple key participants, thereby extending meaning potential not possible with language and re-interpreting the nature of chemical reactions. For example, the rusting of iron could be verbalized as clauses such as 'the iron rusts' or 'iron reacts with oxygen'. But the two clauses are characterized by the one single Medium configuration where 'iron' is the only key participant to actualize the process (Halliday, 1994., pp. 163-164). However, in the corresponding symbolic interpretation, both participants ' $\mathrm{Fe}$ ' and ' $\mathrm{O}_{2}$ 'are equally important to actualize the reactive process ' $\mathrm{Fe}+\mathrm{O}_{2}$ ', as evidenced by the fact that the grammatical makeup can be changed to ' $\mathrm{O}_{2}+\mathrm{Fe}$ ' without much change of meaning.

\section{Conflation of Things and Qualities in Chemical Symbolism}

Whereas linguistic nominal groups construe meaning as things or qualities (Halliday \& Matthiessen 1999, p. 184), chemical symbols realize conflated meanings of both things and qualities ${ }^{2}$, thereby simultaneously meeting the contextual requirements of submicroscopic interpretation and quantification of chemistry. For instance, the symbol ' $\mathrm{Fe}$ ' could not only refer to an iron atom but also perform the function as quantity of 56 in term of relative atomic mass at the same time. Chemical symbolism's new meaning of quantity might be useful to explain why students often find chemistry too mathematical (Chittleborough, 2004) and why the operative process in mathematics plays a crucial role in the symbolic construction of chemistry. Due to the semantic affordance of quantity, chemical symbols can easily enter the operative process such as ' $5 \mathrm{Fe}$ ' while it is not possible with the linguistic correspondence 'iron'.

The semantic conflation of things and qualities in chemical symbolism might be best demonstrated in balanced chemical equations. For example, on the left side of the equation ' $4 \mathrm{Fe}+3 \mathrm{O}_{2} \rightarrow 2 \mathrm{Fe}_{2} \mathrm{O}_{3}$ ', the plus sign functioning as the process verb refers to 'react with' and 'add to' at the same time. That is to say, the symbolic representation of ' $4 \mathrm{Fe}+3 \mathrm{O}_{2}$ ' construes both a reactive process and an operative process of addition, which are fused together when the plus sign constitutes the shared center of two nuclear configurations. It therefore might be argued that through the semantic conflation, chemical symbolism has the potential to interpret both the qualitative and quantitative attributes of the reaction simultaneously in the most economical way, thereby constituting a powerful meaning making resource to realize the law of conversation of mass. 
While the dual valeurs of things and qualities in chemical symbolism provide an efficient way to quantify chemistry and achieve structural condensations, over-emphasis on the quantitative aspect of chemistry might make students find it difficult to distinguish chemical symbolism from mathematical symbolism and overlook the significance of the former's submicroscopic meaning. To examine these concerns we may consider a chemical equation balancing instruction from a recommended Singapore secondary textbook displayed in Figure 1.

\begin{tabular}{|c|c|}
\hline Step 1: Write the formula. & $\mathrm{H}_{2}+\mathrm{O}_{2} \rightarrow \mathrm{H}_{2} \mathrm{O}$ \\
\hline Step 2: Count the atoms. & 21 \\
\hline Step 3: Add '2' in front of $\mathrm{H}_{2} \mathrm{O}$ & $\mathrm{H}_{2}+\mathrm{O}_{2} \rightarrow 2 \mathrm{H}_{2} \mathrm{O}$ \\
\hline Step 4: Count the atoms again. & 42 \\
\hline Step 5: Add ' 2 ' in front of $\mathrm{H}_{2}$ & $2 \mathrm{H}_{2} \mathrm{O}$ \\
\hline
\end{tabular}

\section{Figure 1. One Example of Instructions on Chemical Equation Balancing (adapted from Onn, Ang, \& Khoo, 2006, p. 59)}

From the social semiotic perspective, the above instruction might be misleading for it totally excludes the discussion of the reactive process, which is frequently fused with the operative process in the symbolic representation of chemical reactions. Since none of the five steps explains the reactive process, students might mistake the chemical symbols of $\mathrm{H}$ and $\mathrm{O}$ for mathematical variables such as $\mathrm{X}$ and $\mathrm{Y}$ and thus conceive the nature of chemical reactions as mere mathematical calculations. This misconception will even be exacerbated, given that the chemical equation balancing exercises appear in the textbook (Onn, Ang, \& Khoo, 2006, p. 59) before the introduction of atomic structures (Onn, Ang, \& Khoo, 2006, pp. 65-68) when students have little understanding of the submicroscopic meaning of chemical reactions.

\section{Exploitation of Spatial Graphology}

If chemical formulae are merely conceived as algorithmic operations, students also run the risk of misunderstanding the significance of spatial graphology in chemical discourse. For example, supposing $\mathrm{H}_{2}$ is interpreted 
only as an addition of two hydrogen atoms, there will be no difference between it and $2 \mathrm{H}$, for their sums of hydrogen atoms equal each other in mathematical sense. However, the chemical formula $\mathrm{H}_{2}$ significantly differs from $2 \mathrm{H}$ : the subscript of 2 encodes special experiential meaning of the reactive process ' $\mathrm{H}+\mathrm{H}$ ' in the former while the latter only involves the operative process of multiplication ' $2 \times \mathrm{H}$ '. In fact, spatial graphology is an important meaning making strategy in chemical symbolism. Parallel to mathematical discourse (O'Halloran, 2005, pp. 112-114), chemistry exploits spatial and positional notation to further condense information. The spatial position of the 4 as a subscript in $\mathrm{CH}_{4}$, for example, constitutes an efficient means to compact the complicated reactive process of ' $\mathrm{H}+\mathrm{H}+$ $\mathrm{C}+\mathrm{H}+\mathrm{H}^{\prime}$ in methane.

Cajori (1993, cited in O'Halloran, 2005, p. 111) points out that the choice of a particular symbol does not depend upon its inherent merit but upon circumstantial, personal and political contingencies. One example in chemical discourse is the evolution of spatial notations. In the early $19^{\text {th }}$ century, Berzelius introduced the superscript system to denote the number of atoms in a molecule (e.g. ' $\mathrm{S}^{2} \mathrm{O}^{3 \text { ' }}$ for hyposulphuric acid). In order to avoid the confusion with the power system in mathematics, Lizbig suggested the subscript system in 1834 as the alternative expression (Brock, 1993, pp. 154-155). However, until the early $20^{\text {th }}$ century French chemists were still using superscripts. Accordingly, there seems to be no smooth path to standardized chemical symbolic notion.

\section{CONCLUSION}

As may be clear from the preceding discussion, chemical symbolism is neither a jargon nor shorthand for verbal representations of scientific reality. On the contrary, in response to the contextual requirements of quantification and submicroscopic interpretation, chemical symbolism developed specialized grammatical strategies to construe topological meaning and sub-microscopic meaning at abstract levels, which may be transparent for expert chemists to understand, but constitute a serious challenge for novice learners in science education.

Students' poor understanding of chemical symbolism is dominantly attributed to their lack of knowledge on the specific conventions associated with the mode (Gilbert, 2005, p. 18), and thus educators need to teach the code of symbolism. However, since the notion of convention or code has a 
strong connotation that symbolism is driven by strict rules, pedagogical practice tends to focus on expression. For example, novice learners are told to remember the correct molecular formula for sodium chloride is ' $\mathrm{NaCl}$ ' rather than ' $\mathrm{ClNa}$ '. Admittedly, this kind of knowledge is important. But the issue of meaning is often overlooked, and pupils who never misspell the formula ' $\mathrm{NaCl}$ ' might conceive it merely as a fancy way of saying 'sodium chloride' or 'salt', without understanding their semantic differences.

It therefore follows that in order to improve multiliteracies in chemistry, symbolism (as well as other types of representations) would better be viewed as meaning making resources rather than conventionalized codes, and teachers need to develop explicit instructions on the meaning making patterns of chemical representations. The social semiotic analysis in this research takes a modest step towards the 'metasemiotic knowledge' (Unsworth, 2001) about the functionality of chemical symbols, and suggests a preliminary meta-language to inform the explicit teaching and learning of chemistry. However, further research is needed to explore how the meta-semiotic knowledge and meta-language could be effectively used to aid teaching and learning in pedagogical practice.

\section{Note}

1 Similar to mathematical symbolism (O’Halloran, 1996, 1999, 2000, 2005), chemical equations could be conceived as relational processes. For example, in the chemical equation ' $\mathrm{Cu}+\mathrm{O}_{2} \rightarrow \mathrm{CuO}$ ', the reaction between ' $\mathrm{Cu}$ ' and ' $\mathrm{O}_{2}$ ' is the Token and the product ' $\mathrm{CuO}$ ' is the Value while the arrow sign serving the role of process has the meaning similar to 'turn into' and thus is characteristic of identifying modes (Halliday, 1994: p.123). In addition, the left- to -right directionality indicated by the arrow suggests a temporal sequence between the reactants and the products, which construes the whole equation as a circumstantial identifying clause.

${ }^{2}$ Following Halliday \& Matthiessen (1999, p. 211), quantity is a subtype of qualities.

\section{REFERENCES}

Brock, W. (1993). The Norton history of chemistry. New York: Norton.

Chittleborough, G. D. (2004). The role of teaching models and chemical representations in developing students' mental models of chemical 
phenomena..Unpublished doctoral dissertation, Curtin University of Technology, Perth.

Cope, B., \& Kalantzis, M. (Eds.). (2000). Miltiliteracies: Literacies learning and the design of social futures. Melbourne: Macmillan.

Gilbert, J. K. (Ed.). (2005). Visualization in science education. Dordrecht: Springer.

Halliday, M. A. K. (1978). Language as social semiotic: The social interpretation of language and meaning. London: Edward Arnold.

Halliday, M. A. K. (1994). An introduction to functional grammar $\left(2^{\text {nd }}\right.$ ed.). London: Edward Arnold.

Halliday, M. A. K. (1998). Things and relations: Regrammaticizing experience as technical knowledge. In J. R. Martin, \& R. Veel (Eds.), Reading science: Critical and functional perspectives on discourses of science (pp. 185-235). London: Routledge.

Halliday, M. A. K., \& Hasan, R. (1985). Language, text and context. Victoria: Derkin University.

Halliday, M. A. K., \& Martin, J. R. (1993). Writing science: Literacy and discursive power. London: The Falmer Press.

Halliday, M. A. K., \& Matthiessen, C. (1999). Construing experience through meaning: A language-based approach to cognition. London and New York: Cassell.

Jones, J. (2007). Multiliteracies for academic purposes: A metafunctional exploration of intersemiosis and multimodality in university textbook and computer-based learning resources in science. Unpublished doctoral dissertation, University of Sydney, Sydney.

Kress, G., \& van Leeuwen, T. (1996). Reading images: The grammar of visual design. London: Routledge.

Kress, G., Jewitt, C., Ogborn, J., \& Tsatsarelis, C. (2001). Multimodal teaching and learning: The rhetorics of the science classroom. London: Continuum.

Lemke, J. L. (1998). Multiplying meaning: Visual and verbal semiotics in scientific text. In J. R. Martin, \& R. Veel (Eds.), Reading science: Critical and 
functional perspectives on discourses of science (pp. 87-113). London: Routledge.

Martin, J. R. (1997). Analyzing genre: Functional parameters. In F. Christie, \& Martin, J. R. (Eds.), Genre and institutions: Social processes in the workplace and school (pp. 3-39). London and New York: Continuum.

Martin, J. R. (1999). Modelling context: A crooked path of progress in contextual linguistics. In M. Ghadessy (Ed.), Text and context in functiona linguistics (pp. 25-61). Amsterdam and Philadelphia: John Benjamins.

O'Halloran, K. L. (1996). The discourses of secondary school mathematics. Unpublished doctoral dissertation, Murdoch University, Perth.

O'Halloran, K. L. (1999). Towards a systemic functional analysis of multi-semiotic mathematics texts. Semiotica, 124(1/2), 1-29.

O'Halloran, K. L. (2000). Classroom discourse in mathematics: Multi-semiotic analysis. Linguistics and Education, 10(3), 359-388.

O'Halloran, K.L. (2005). Mathematical discourse: Language, symbolism and visual images. London: Continuum.

O'Halloran, K. L. (2007). Systemic functional multimodal discourse analysis (SFMDA) approach to mathematics, grammar and literacy. In A. McCabe, M. O'Donnell, \& R. Whittaker (Eds.), Advances in language and education (pp. 77-102). London and New York: Continuum.

O'Halloran, K. L. (2008). Systemic functional-multimodal discourse analysis (SFMDA): Constructing ideational meaning using language and visual imagery. Visual Communication, 7(4), 443-475.

Onn, H. L., Ang, J. A., \& Khoo, L. E. (2006). Chemistry expression: An inquiry Approach. Singapore: EPB Pan Pacific.

O’Toole, M. (1994). The language of displayed art. London: Leicester University Press.

Oversby, J. (2003). The development of chemical symbols and syntax as a means of communication about chemical change. Working paper in progress.

Pinker, S. (1994). The language instinct. New York: Morrow. 
Singapore Chemistry GCE Ordinary Level (Syllabus 5067) revised for 2010. (n.d.). Retrieved November 1, 2009, from http://www.seab.gov.sg/SEAB/oLevel/ syllabus/2010_GCE_O_Level_Syllabuses/5067_2010.pdf.

Smith (Eds.), Multimodal studies: Multiple approaches and domains. New York and London: Routledge.

Unsworth, L. (2001). Teaching multiliteracies across the curriculum: Changing contexts of text and image in classroom practice. Buckingham: Open University Press. 